\title{
Inhibitory Effects of Tropical Medicinal Plant Extracts on Urea Hydrolysis and Nitrification in Soil: A Preliminary Study
}

\author{
Muqiu Zhao, Huaibao Zhao, Qianjin Du, and Yunfeng Shi ${ }^{1}$ \\ College of Tropical Biology and Agriculture, Qiongzhou University, No. 1 \\ Yucai Road, Sanya, 572022, P.R. China
}

Additional index words. nitrogen transformation, urease activity, nitrification potential, ammonium oxidizer number, phenols

\begin{abstract}
Hydrolysis and nitrification are the key steps of biological transformation of urea in soils, which control the loss of nitrogen $(N)$ in terrestrial ecosystem. The inhibitory effects of plant materials on $\mathbf{N}$ transformation provide potential benefits for agricultural production and environmental protection. In this study, water-soluble and ethanol-soluble compounds were extracted from 24 tropical medicinal plant species in Hainan Island, southern China, with the aim of measuring their effects on urease activity (UA), nitrification potential (NP), and ammonium oxidizer number in a paddy soil, by a series of short (5 hours) and long-term (14 days) incubation experiments. Total solid yields and phenols contents of $\mathbf{4 8}$ medicinal plant extracts were also analyzed in this study. There were big differences in total solid yield and phenols content among the extracts of the selected tropical medicinal plant extracts. The phenols content of the plant extracts varied from 15.1 to $273.4 \mathrm{mg}$ GAE/g extract (milligrams of gallic acid equivalents per gram of extract). A significant relationship between UA and NP of the soil treated with plant extracts and their phenols content was found, indicating that phenolic compounds are the major contributors to the inhibitory properties of these plants. Further studies indicated that the water extracts of Epimeredi indica aerial and Melia azedarach leaf, containing a high content of phenols, exhibited notable urease and nitrification inhibitory effects and reduced the number of soil ammonia-oxidizing bacteria, being promising sources of natural inhibitors for soil $\mathbf{N}$ transformation.
\end{abstract}

Urea has become one of the most commonly used $\mathrm{N}$ fertilizers in the world due to its high $\mathrm{N}$ content, stable nature, easy application, and other characteristics (Subbarao et al., 2012). However, urea applied to the soil surface can be rapidly hydrolyzed into ammonia $\left(\mathrm{NH}_{3}\right)$ or ammonium $\left(\mathrm{NH}_{4}^{+}\right)$by soil urease, which easily causes $\mathrm{NH}_{3}$ volatilization and leads to high concentration of $\mathrm{NH}_{3}$ in soil microzone, thus harming germinating seedlings and young plants (Subbarao et al., 2013). In addition, $\mathrm{NH}_{4}{ }^{+}$can be easily transformed into nitrate $\left(\mathrm{NO}_{3}^{-}\right)$via nitrification and $\mathrm{NO}_{3}{ }^{-}$may be lost in harmful forms of nitrous oxide $\left(\mathrm{N}_{2} \mathrm{O}\right)$ and nitric oxide $(\mathrm{NO})$ by denitrifying bacteria or leaching through the soil to contaminate groundwater (Arango

Received for publication 18 Feb. 2015. Accepted for publication $18 \mathrm{Feb} .2015$.

This study was supported by the Natural Science Foundation of Hainan Province (312100), the National Natural Science Foundation of China (41301324), the National Science and Technology Support Program of China (2011BAD11B04), and the Program for Hainan cultivated land improvement (HNGDg121501).

We gratefully acknowledge Zhunian Wang from Chinese Academy of Tropical Agricultural Sciences for the assistance in plant species identification.

${ }^{1}$ To whom reprint requests should be addressed; e-mail shiyunfeng8189@sina.com. et al., 2014). Overall, the losses of $\mathrm{N}$ fertilizers may exceed $70 \%$ of the total application amount and cause serious environmental issues (Upadhyay et al., 2011).

Therefore, to ensure continuous and optimal $\mathrm{N}$ supply, improve use efficiency of $\mathrm{N}$ fertilizers, and protect the environment, regulation strategies should be adopted based on reducing urea hydrolysis and nitrification. Adding urease inhibitors into urea or nitrification inhibitors into $\mathrm{NH}_{4}{ }^{+}$form and amide $\mathrm{N}$-form fertilizers is an appropriate choice (Zaman et al., 2009). A large number of studies have been conducted on urease inhibitors such as $\mathrm{N}$-( $n$-butyl)thiophosphoric triamide (NBPT), phenyl phosphorodiamidate (PPD), and hydroquinone (HQ), as well as nitrification inhibitors such as dicyandiamide (DCD), nitrapyrin (N-serve), and 3,4-dimethylpyrazole phosphate (DMPP), some of which have been confirmed to have excellent potential to improve use efficiency of $\mathrm{N}$ and reduce environmental risks of applying $\mathrm{N}$ fertilizers (Arora and Srivastava, 2013). However, due to their high prices, poor availability, and adverse influences on beneficial microorganisms in the soil, most of synthesized urease and nitrification inhibitors are limited to the experimental stage and are not suitable to be popularized in agricultural production practice, especially in developing countries.
Phenolic compounds isolated from certain plants influence $\mathrm{N}$ cycling, which results in a decrease of $\mathrm{N}$ losses and represents a key issue for environmental protection worldwide. Plant metabolites and plant-based biochemical metabolic inhibitors have been considered as the best alternatives to synthetic urease and nitrification inhibitors due to their minimal environmental impact and biological damage (Patra et al., 2006). Therefore, the search for inhibitors from natural sources has received much attention, and efforts have been made to identify new natural resources for $\mathrm{N}$ efficiency improving compounds. Previous studies have shown that a number of extracts derived from higher plants can effectively inhibit UA and NP. Many empirical studies have pointed out that some plants and their by-products can inhibit urea hydrolysis or nitrification or both. To be specific, karanja (Pongamia glabra), neem (Azadirachta indica), and mint (Mentha spicata) are important sources of natural inhibitors (Abbasi and Manzoor, 2013; Kiran and Patra, 2003; Opoku et al., 2014).

A wide variety of tropical medicinal plants that are traditionally used to cure diseases, or to maintain and improve health, have been developed and applied to disinfection, sterilization, virus inactivation, antioxidation, and cosmetics (Schmidt, 2012). The aim of this study was to evaluate the inhibitory effects of extracts obtained from a small part of medicinal plant species that grow in Hainan Island, southern China, on urea hydrolysis and nitrification in soil, to obtain some biodegradable, eco-friendly, and inexpensive natural compounds capable of increasing N-use efficiency in agricultural soils. Moreover, this study is focused on the relationship between phenols in the extracts of selected medicinal plants and their urease/nitrification inhibitory effects. The phenolic compounds constitute a large group of secondary plant metabolites that are ubiquitous among higher plants. They are natural compounds, which generally help plants for defense, and widely known antibacterial agents that inhibit the activity of bacteria and fungi (Rauha et al., 2000).

\section{Materials and Methods}

Soil. In the present study, a paddy soil originated in granite latosol was used. The soil was collected from Miaolin Farm at Fenghuang town, Sanya, Hainan Province, China $\left(18.305^{\circ} \mathrm{N}, 109.463^{\circ} \mathrm{E}\right)$, with a $\mathrm{pH}$ of 5.24 (soil:water $=1: 2.5, \mathrm{w} / \mathrm{v})$, organic matter of $18.65 \mathrm{~g} \cdot \mathrm{kg}^{-1}$, total $\mathrm{N}$ of $1.16 \mathrm{~g} \cdot \mathrm{kg}^{-1}, \mathrm{NH}_{4}{ }^{+}-\mathrm{N}$ of $6.2 \mathrm{mg} \cdot \mathrm{kg}^{-1}$, and $\mathrm{NO}_{3}{ }^{-} \mathrm{N}$ of $17.4 \mathrm{mg} \cdot \mathrm{kg}^{-1}$. Composite samples were taken at $0-10 \mathrm{~cm}$ of depth. Moist field soil samples were sieved through $2 \mathrm{~mm}$ to remove stone and plant roots and then stored at $-10{ }^{\circ} \mathrm{C}$ to inhibit biological activity. The original UA and NP of the moist soil were $32.4 \mathrm{mg}$ Urea$\mathrm{N}$ per $\mathrm{kg}^{-1} \cdot \mathrm{h}^{-1}$ and $0.925 \mathrm{mg} \mathrm{NO}_{2}^{-}-\mathrm{N}$ per $\mathrm{kg}^{-1} \cdot \mathrm{h}^{-1}$, respectively, measured with the 
Table 1. Total solid yields and phenols contents of water- and ethanol-extracted plant extracts and urease activity (UA) and nitrification potential (NP) in the plant extract-treated soil under 5-h incubation. The data were shown as means of triplicated measurements with SD. The plant extracts for further study are also identified.

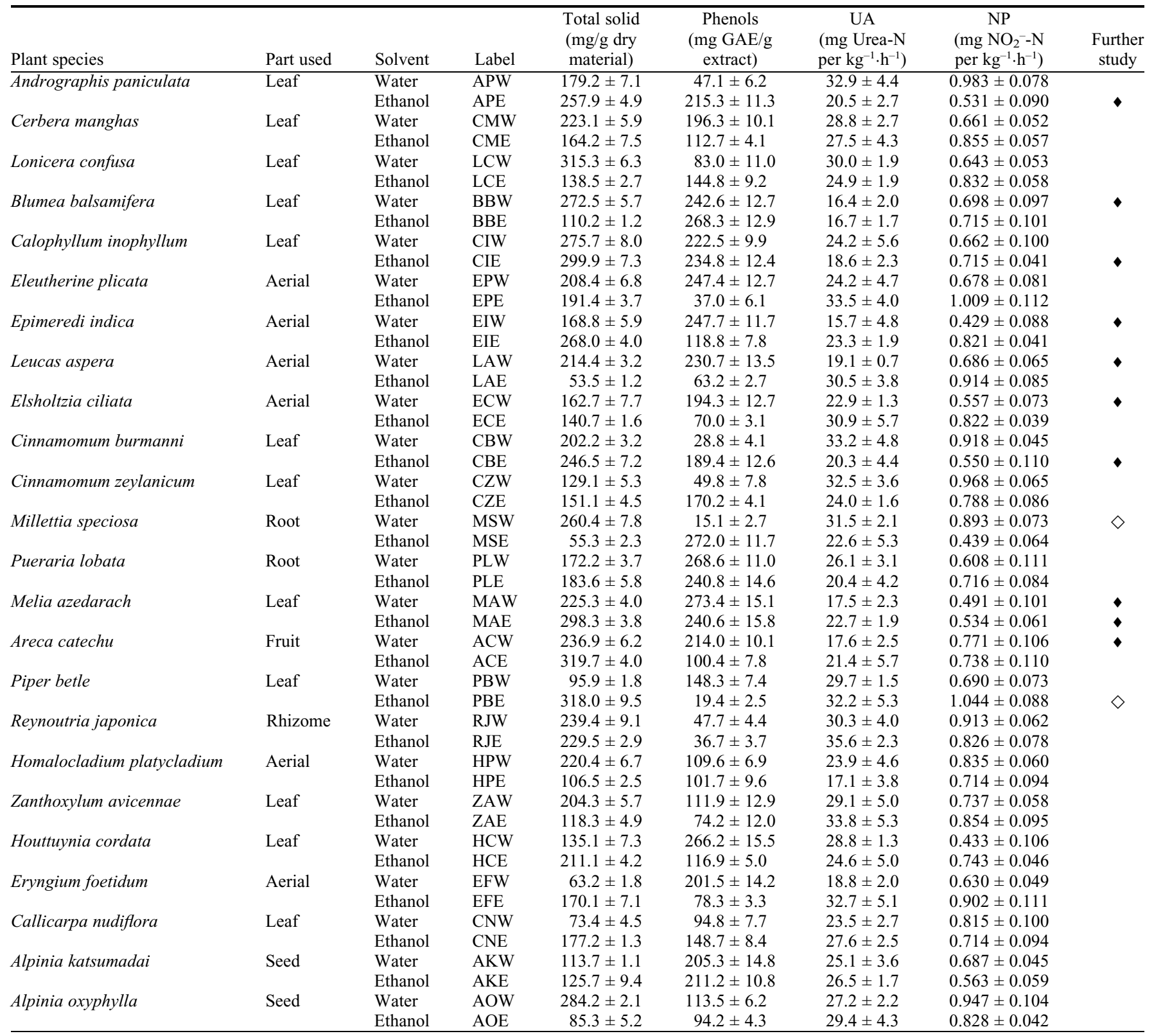

$\checkmark$ : The plant extract selected for the further study according to certain criteria.

$\diamond:$ The plant extract selected for the further study as the representative with low phenols content.

same methods as described in the following short-term incubational experiments.

Tropical medicinal plant materials and their extracts. A total of 24 species of tropical medicinal plants were collected from Danzhou Tropical Medicinal Plant Germplasm Resource Nursery, Chinese Academy of Tropical Agricultural Sciences during Sept. and Dec. 2013. The selection of the plant materials in the present study was based on their potential medicinal uses and their distribution in sampling locations. The Latin names of the plant species, used parts, and labels in this article were shown in Table 1. Plant samples were brought back to the laboratory, washed, air-dried, crushed into powder with a particle size of less than $0.37 \mathrm{~mm}$, and preserved under dark refrigerated condition.
The powdered plant samples were dissolved in water or ethanol at the ratio of 1:10 (solid:liquid, w/v) and ultrasonically extracted for $20 \mathrm{~min}$. The extracts were centrifuged at the speed of $12,000 \mathrm{rpm}$ for $10 \mathrm{~min}$. The residues were extracted twice with the same fresh solvent, and all the extracts combined. Water and organic extracts were concentrated in a rotary evaporator, and then the extracts were freeze-dried. After that, the solid matters were weighted and the total solid yields were calculated and expressed in terms of milligrams of extracts per gram of dry weight material (Table 1). The phenols content of plant extracts was determined by the spectrophotometric method using Folin-Ciocalteu reagent, with gallic acid (GA) as the standard (Singleton et al., 1999). The results were expressed in terms of milligrams of GA equivalents per gram of extract (mg GAE/g extract) (Table 1).

Short-term incubation experiments. The effects of the 48 tropical medicinal plant extracts obtained with water and ethanol on soil UA and NP were assayed by the following short-term incubation experiments.

The soil UA in short-term incubation was determined with urea- $\mathrm{N}$ residual method (Tabatabai, 1994). Briefly, a $5 \mathrm{~mL}$ of urea solution ( $2 \mathrm{mg}$ urea-N/mL) containing $0.25 \mathrm{mg}$ of plant extract was added to $5 \mathrm{~g}$ of soil, incubating at $37^{\circ} \mathrm{C}$ for $5 \mathrm{~h}$. After that, the soil was extracted with a $50 \mathrm{~mL}$ of $\mathrm{KCl}\left(2 \mathrm{~mol} \cdot \mathrm{L}^{-1}\right)$-phenyl mercuric acetate $\left(5 \mathrm{mg} \cdot \mathrm{L}^{-1}\right)$ solution, and urea-N content was estimated. The results were expressed in 
terms of the amount of decomposed urea-N $(\mathrm{mg})$ per kilogram of soil per hour (mg Urea$\mathrm{N}$ per $\left.\mathrm{kg}^{-1} \cdot \mathrm{h}^{-1}\right)$.

The soil NP in short-term incubation was determined with $\mathrm{NO}_{2}^{-}-\mathrm{N}$ production method (Schinner et al., 1996). Four shares of soil samples $(5 \mathrm{~g})$ were transferred into $50 \mathrm{~mL}$ flasks, added with $20 \mathrm{~mL}$ of substrate solution $\left(\mathrm{NH}_{4}{ }^{+}-\mathrm{N}, 14 \mathrm{mg} \cdot \mathrm{L}^{-1}\right)$ containing $0.25 \mathrm{mg}$ of plant extract, and $0.2 \mathrm{~mL}$ of sodium chlorate solution $\left(1.5 \mathrm{~mol} \cdot \mathrm{L}^{-1}\right)$ to prevent the oxidation of generated $\mathrm{NO}_{2}{ }^{-}$into $\mathrm{NO}_{3}^{-}$. Three shares of soil samples were incubated at $25{ }^{\circ} \mathrm{C}$ with shaking for $5 \mathrm{~h}$; the other share [control check (CK)] was frozen at $-20^{\circ} \mathrm{C}$ for $5 \mathrm{~h}$. After the 5 -h incubation (frozen sample should be thawed), soil samples were added with $5 \mathrm{~mL}$ of $\mathrm{KCl}$ solution $\left(2 \mathrm{~mol} \cdot \mathrm{L}^{-1}\right)$, mixed evenly, and filtered. $\mathrm{NO}_{2}^{-}-\mathrm{N}$ content was determined by the amino-benzenesulfonamide method. The results were expressed as $\mathrm{mg} \mathrm{NO}_{2}{ }^{-} \mathrm{N}$ per $\mathrm{kg}^{-1} \cdot \mathrm{h}^{-1}$.

Plant extracts selection for further study. Out of the total number (48) of plant extracts, 10 extracts were selected (marked with $\bullet$, Table 1) under the following criteria: plant extracts with high total solid yield $(>150 \mathrm{mg} / \mathrm{g}$ dry material) and high content of phenols (>150 mg GAE/g extract); and low UA $\left(<20 \mathrm{mg}\right.$ Urea-N per $\left.\mathrm{kg}^{-1} \cdot \mathrm{h}^{-1}\right)$ and NP $(<0.6$ $\mathrm{mg} \mathrm{NO}_{2}^{-}-\mathrm{N}$ per $\mathrm{kg}^{-1} \cdot \mathrm{h}^{-1}$ ) performed in the short-term incubation experiments. In addition, two plant extracts that did not fulfill the criteria above were selected to determine if such plant extracts with low phenols content could affect soil $\mathrm{N}$ transformation (identified with the symbol $\diamond$, Table 1 ).

Long-term incubation experiment (further study). A 14-d long-term incubation experiment was conducted to investigate the effects of the selected tropical medicinal plant extracts on soil $\mathrm{N}$ transformation. The soil was fertilized with a urea solution (according to $150 \mathrm{mg} \mathrm{N} / \mathrm{kg}$ soil) containing a specific plant extract (according to $50 \mathrm{mg} / \mathrm{kg}$ soil), mixed evenly and transferred into polyethylene flasks, and then incubated at $60 \%$ water-filled pore space (WFPS) at $25{ }^{\circ} \mathrm{C}$. A control treatment without plant extract addition in the soil was also included. Soil subsamples were taken for the measurement of urea content and soil UA, after 48-h incubation. At the end of the 14-d incubation, soil subsamples were assayed for $\mathrm{NO}_{3}{ }^{-}-\mathrm{N}$ content, $\mathrm{NP}$, and ammonium oxidizer number.

The soil UA and NP were measured as the short-term incubation experiments described above; urea content was determined by the amino-benzenesulfonamide method; $\mathrm{NO}_{3}{ }^{-}-\mathrm{N}$ content was measured using a continuous flow autoanalyzer (Auto-Analyzer III, Germany); and the number of ammonium-oxidizing bacteria was measured with the most probable number method.

Data processing and statistics. The inhibitory effects of the plant extracts on urea hydrolysis and nitrification in the long-term incubation experiment were quantified by urease inhibitory rate and nitrification inhibitory rate, respectively. The specific calculation methods were as follows:

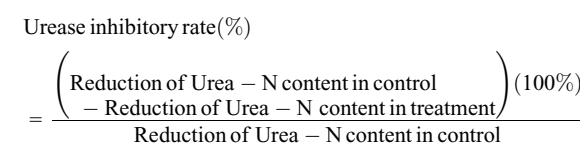

Nitrification inhibitory rate(\%)

$=\frac{\left(\begin{array}{c}\text { Increment of } \mathrm{NO}_{3}^{-}-\mathrm{N} \text { content in control } \\ - \text { Increment of } \mathrm{NO}_{3}^{-}-\mathrm{N} \text { content in treatment }\end{array}\right)(100 \%)}{\text { Increment of } \mathrm{NO}_{3}^{-}-\mathrm{N} \text { content in control }}$

All treatments were conducted in triplicate and all data were analyzed statistically with oneway analysis of variance and the Duncan test $(P<0.05)$ using SPSS 18.0 (IBM, New York, NY). Linear regression analysis was performed using OriginPro 7.0 (OriginLab, Northampton, MA).

\section{Results}

Total solid and phenols of plant extracts. There was a wide range of total solid yields in the water and ethanol plant extracts analyzed, as shown in Table 1 . The values varied from 53.5 (the ethanol extract of Leucas aspera aerial, LAE) to $319.7 \mathrm{mg} / \mathrm{g}$ dry material (the ethanol extract of Areca catechu fruit, ACE), which represents a variation of $\approx 6$-fold. Twenty-three extracts showed a total solid yield higher than $200 \mathrm{mg} / \mathrm{g}$ dry material, being about half of the total extract samples. Three extracts showed a very high total solid yield ( $>300 \mathrm{mg} / \mathrm{g}$ dry material): ACE, ethanol extract of Piper betle leaf (PBE), and water extract of Lonicera confusa leaf (LCW) extracts. Among the experimental plants, six extracts showed a very low total solid yield $(<100 \mathrm{mg} / \mathrm{g}$ dry material), equaling to $12.5 \%$ of the total extract samples.

There was also a wide range of phenols contents in the plant extracts as shown in Table1. The values varied from 15.1 to $273.4 \mathrm{mg} \mathrm{GAE} / \mathrm{g}$ extract (average $150.4 \mathrm{mg}$ GAE/g extract) as measured by the FolinCiocalteu method. There were 18 plant extracts (equal to $37.5 \%$ ) with a content of phenols higher than $200 \mathrm{mg} \mathrm{GAE} / \mathrm{g}$ extract, and 15 extracts (equal to $31.3 \%$ ) lower than $100 \mathrm{mg}$ $\mathrm{GAE} / \mathrm{g}$ extract.

The content of phenols in some plant extracts was not directly related to the total solid yield, where the most notable case was the PBE extract. Its total solid yield was almost the highest $(318 \mathrm{mg} / \mathrm{g}$ dry material), whereas its phenols content was extremely low (only $19.4 \mathrm{mg} \mathrm{GAE} / \mathrm{g}$ extract). The ethanol extract of Andrographis paniculata leaf (APE), water extract of Blumea balsamifera leaf (BBW), water extract of Calophyllum inophyllum leaf (CIW), ethanol extract of C. inophyllum leaf (CIE), water extract of Eleutherine plicata aerial (EPW), water extract of $L$. aspera aerial (LAW), water extract of Melia azedarach leaf (MAW), ethanol extract of $M$. azedarach leaf (MAE), and water extract of $A$. catechu fruit (ACW) were the plant extracts with high solid yield and phenols content.

Soil UA and NP in short-term incubation experiments. Considering this study was the primary stage, the plant species used in this study were selected based on traditional medicinal knowledge and the random distribution in sampling sites. Most of the water and ethanol extracts of these plants exhibited inhibitory effects on soil UA and NP, compared with the original soil UA and NP. To be specific, the soil samples treated with BBW, ethanol extract of B. balsamifera (BBE), CIE, water extract of Epimeredi indica aerial (EIW), LAW, MAW, ACW, ethanol extract of Homalocladium platycladium aerial (HPE), and water extract of Eryngium foetidum aerial (EFW) presented UAs lower than 20 mg Urea-N per $\mathrm{kg}^{-1} \cdot \mathrm{h}^{-1}$, and the same amount of treatments (APE, EIW, water extract of Elsholtzia ciliata aerial (ECW), ethanol extract of Cinnamomum burmanni leaf (CBE), ethanol extract of Millettia speciosa root (MSE), MAW, MAE, water extract of Houttuynia cordata leaf (HCW), and ethanol extract of Alpinia katsumadai seed (AKE) exhibited NPs lower than $0.6 \mathrm{mg} \mathrm{NO}_{2}^{-}-\mathrm{N}$ per $\mathrm{kg}^{-1} \cdot \mathrm{h}^{-1}$. It is worth noting that EIW and MAW not only effectively inhibited urea hydrolysis but also had significant inhibitory effects on nitrification, being promising sources of natural inhibitors for soil $\mathrm{N}$ transformation.

The following plant extracts were selected according to the previously established criteria for the further study: APE, BBW, CIE, EIW, LAW, ECW, CBE, MAW, MAE, and ACW. In addition, water extract of $M$. speciosa root (MSW) and PBE were selected to demonstrate whether other nonphenolic compounds can affect soil $\mathrm{N}$ transformation.

Effects of selected tropical medicinal plant extracts on soil $U A, N P$, and ammonium oxidizer number in long-term incubation experiment. The urease inhibitory rates and the UAs of the soil treated with the selected medicinal plant extracts and the control were measured after $2 \mathrm{~d}$ of incubation. This time was used because urea hydrolysis usually occurs before $48 \mathrm{~h}$ at $25^{\circ} \mathrm{C}$. The UA of control soil was $42.1 \mathrm{mg}$ Urea-N per $\mathrm{kg}^{-1} \cdot \mathrm{h}^{-1}$ and slightly increased compared with the original value (32.4 mg Urea-N per kg ${ }^{-1} \cdot \mathrm{h}^{-1}$ ). The soil treated with MAW, BBW, ACW, APE, and EIW extracts had a UA of 12.3, 14.7, 16.1, 18.5 , and $19.8 \mathrm{mg}$ Urea-N per $\mathrm{kg}^{-1} \cdot \mathrm{h}^{-1}$, respectively, which was significantly lower than the other treatments (Fig. 1A). The urease inhibitory rates of the selected plant extracts varied with a wide range of $3.5 \%$ to $46.7 \%$ (Fig. 2A). Almost all of the plant extracts had a urease inhibitory rate higher than $20 \%$, except for the two extracts with low phenols content (MSW, 3.5\% and PEB, $11.3 \%$ ). The highest urease inhibitory rates appeared when the soil was treated with EIW, MAW, and CIE extracts, being 46.7\%, $43.8 \%$, and $42.1 \%$, respectively.

The NP of control soil was $1.142 \mathrm{mg}$ $\mathrm{NO}_{2}^{-}-\mathrm{N}$ per $\mathrm{kg}^{-1} \cdot \mathrm{h}^{-1}$ after 2 weeks incubation. All of the soil treatments with plant extracts had NPs lower than the control, among which MAW and ECW were the lowest $(<0.8 \mathrm{mg}$ $\mathrm{NO}_{2}^{-}-\mathrm{N}$ per $\mathrm{kg}^{-1} \cdot \mathrm{h}^{-1}$, Fig. 1B). The EIW and MAW extracts had the highest nitrification inhibitory rates, exceeding 50\% (Fig. 2B). 

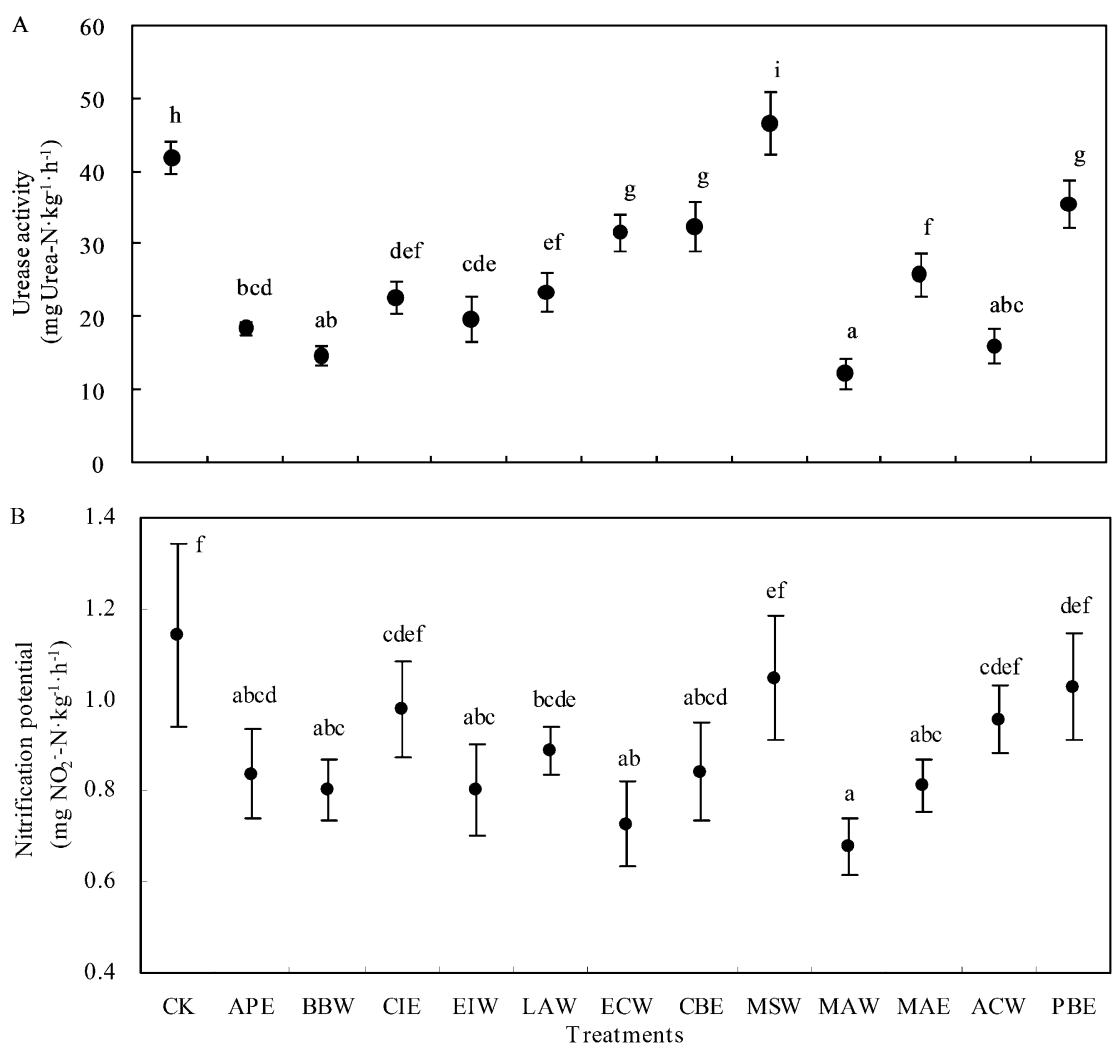

Fig. 1. The urease activities (UAs, A) and nitrification potentials (NPs, B) of soil samples treated with selected tropical medicinal plant extracts in the long-term (14-d) incubation experiment. Error bars indicate SD of the mean $(n=3)$ and different letters indicate significant differences among treatments (Duncan test, $P<0.05$ ). APE $=$ ethanol extract of $A$. paniculata leaf; $\mathrm{BBW}=$ water extract of $B$. balsamifera leaf; $\mathrm{CIE}=$ ethanol extract of $C$. inophyllum leaf; $\mathrm{EIW}=$ water extract of $E$. indica aerial; $\mathrm{LAW}=$ water extract of $L$. aspera aerial $; \mathrm{ECW}=$ water extract of $E$. ciliate aerial; $\mathrm{CBE}=$ ethanol extract of $C$. burmanni leaf; MSW = water extract of $M$. speciosa root; MAW = water extract of $M$. azedarach leaf; $\mathrm{MAE}=$ ethanol extract of $M$. azedarach leaf; $\mathrm{ACW}=$ water extract of $A$. catech $u$ fruit; $\mathrm{PBE}=$ ethanol extract of $P$. betle leaf.

The ammonium oxidizer numbers of all the treatments were suppressed, except for the PBE-treated soil with a slight increase (Fig. 3 ). The treatments with the highest inhibitory effects on ammonium oxidizer number were EIW, CBE, and ECW, in which the numbers of ammonium-oxidizing bacteria were decreased by $59.3 \%, 51.9 \%$, and $48.1 \%$, respectively.

\section{Discussion}

Agricultural systems become more dependent on $\mathrm{N}$ application, because natural $\mathrm{N}$ cycling is insufficient to maintain high productivity. $\mathrm{N}$ transformations in the soil cause different $\mathrm{N}$ fluxes and losses, including $\mathrm{NO}_{3}{ }^{-}$ leaching, $\mathrm{NH}_{3}$ volatilization, and emissions of $\mathrm{NO}$ and $\mathrm{N}_{2} \mathrm{O}$. In general, low efficiencies in absorption by crops are the main reason for $\mathrm{N}$ losses from disturbed terrestrial ecosystems, while a reduction of $\mathrm{N}$ transformation in soils seems to be an efficient way to improve the $\mathrm{N}$ utilization efficiency but reduce $N$ loss. Several studies indicate that some plant species are capable of producing secondary metabolites as an adaptation mechanism that promotes the preservation of organic $\mathrm{N}$ in the soil and reduces $\mathrm{NO}_{3}^{-}$loss by nitrification (Suescun et al., 2012). This research focused on the tropical medicinal plants hydrolysis and $\mathrm{NH}_{4}^{+}$nitrification. The results of this study clearly demonstrated that some tropical medicinal plant extracts rich in secondary metabolites growing in Hainan Island, southern China, can significantly affect soil $\mathrm{N}$ transformation processes, some of which, such as EIW and MAW, are potential alternatives for improving $\mathrm{N}$ efficiency in agriculture production.

Among the inhibitory compounds proposed, phenols, alkaloids, isothiocyanates, and terpenoids have received some attention, especially the phenolic derivatives (Subbarao et al., 2009). It is well known that plant phenols are widely distributed in the plant tissues and that they are sometimes present at surprisingly high contents. DeLuca et al. (2002) indicated that the exudation of phenols through the roots of Pinus sylvestris had a positive influence on $\mathrm{N}$ mineralization, increasing $\mathrm{NH}_{4}{ }^{+}$availability and decreasing nitrification in boreal forest soil in Sweden. Northup et al. (1995) reported a polyphenol from the decomposing Pinus muricata litter, which could influence the proportion of $\mathrm{N}$ released in dissolved organic forms relative to mineral forms $\left(\mathrm{NH}_{4}^{+}\right.$and $\left.\mathrm{NO}_{3}{ }^{-}\right)$. The research of Purnomo et al. (2012) suggested that various trees (mahogany, teak, jackfruit, mango, and breadfruit) litter containing tannin (a kind of phenolic compound) could be used as nitrification inhibitors for increasing $\mathrm{N}$ fertilizer efficiency for soybean in agroforestry system. Baldwin et al. (1983) indicated that nitrification in a highly active $\mathrm{Al}$ horizon of a balsam fir forest floor soil could be greatly inhibited by an aqueous methanol extract of the forest floor, in which condensed tannins (a kind of smaller molecular weight phenols) were the most important inhibiting components. When all phenolic materials were removed from the extract, the remaining solution stimulated nitrification.

The results of the present study also indicated that phenolic compounds were probably the major contributors to the inhibitory properties of these plants because the plant extracts containing higher contents of phenols always exhibited stronger influence on soil UA and NP (Fig. 1; Table 1). In the long-term incubation experiment, the higher urease and nitrification inhibitory rates also corresponded with the soils treated with the plant extracts with higher contents of phenols. Furthermore, based on the data of short-term experiments, significant linear correlation existed between phenols content and soil UA $(R=0.739, n=48, P<0.001)$ or NP $(R=0.826, n=48, P<0.001)$ (Fig. 4).

It is well known that plant polyphenols possess universal inhibitory effect on most of the microbes under neutral and weak acidic conditions (Rauha et al., 2000). Although the mechanisms of natural inhibitors for soil $\mathrm{N}$ transformation are diverse and not well understood, the effects were possibly based on the following reasons: 1) The toxic effect of phenols to soil microbes. As a basic chemical property, plant phenols can combine with proteins through hydrophobic and hydrogen bonds. In this study, the application of some 

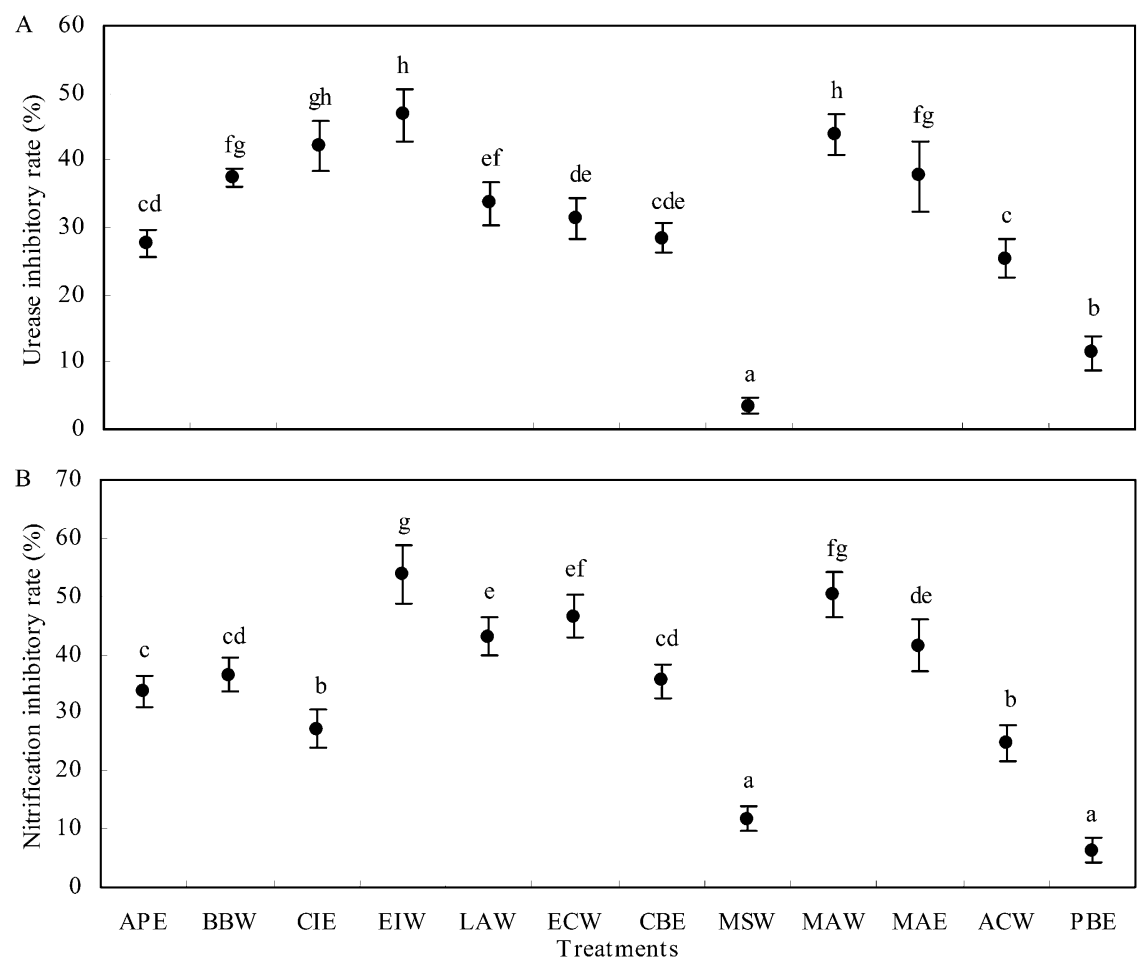

Fig. 2. The urease inhibitory rates $(\mathbf{A})$ and nitrification inhibitory rates $(\mathbf{B})$ of selected tropical medicinal plant extracts in the long-term (14-d) incubation experiment. Error bars indicate SD of the mean $(n=3)$ and different letters indicate significant differences among treatments (Duncan test, $P<0.05$ ). APE $=$ ethanol extract of $A$. paniculata leaf; $\mathrm{BBW}=$ water extract of $B$. balsamifera leaf; $\mathrm{CIE}=$ ethanol extract of $C$. inophyllum leaf; $\mathrm{EIW}=$ water extract of $E$. indica aerial; $\mathrm{LAW}=$ water extract of $L$. aspera aerial; $\mathrm{ECW}=$ water extract of $E$. ciliate aerial; $\mathrm{CBE}=$ ethanol extract of $C$. burmanni leaf; $\mathrm{MSW}=$ water extract of $M$. speciosa root; $\mathrm{MAW}=$ water extract of $M$. azedarach leaf; $\mathrm{MAE}=$ ethanol extract of $M$. azedarach leaf; $\mathrm{ACW}=$ water extract of $A$. catech $u$ fruit; $\mathrm{PBE}=$ ethanol extract of $P$. betle leaf.

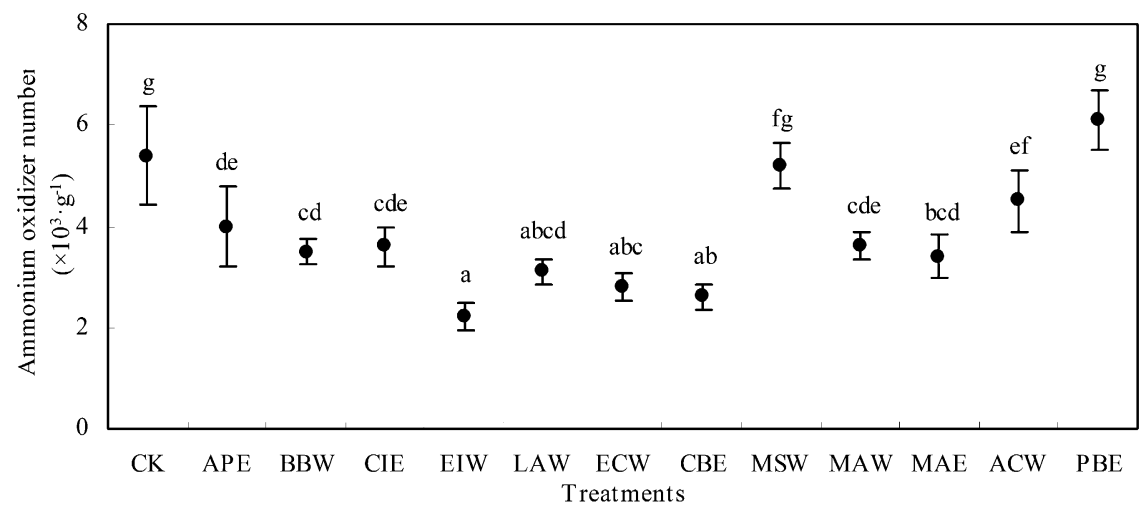

Fig. 3. The ammonium oxidizer numbers of soil samples treated with selected tropical medicinal plant extracts in the long-term (14-d) incubation experiment. Error bars indicate SD of the mean $(n=3)$ and different letters indicate significant differences among treatments (Duncan test, $P<0.05$ ). APE $=$ ethanol extract of $A$. paniculata leaf; $\mathrm{BBW}=$ water extract of $B$. balsamifera leaf; $\mathrm{CIE}=$ ethanol extract of $C$. inophyllum leaf; $\mathrm{EIW}=$ water extract of $E$. indica aerial; $\mathrm{LAW}=$ water extract of $L$. aspera aerial; $\mathrm{ECW}=$ water extract of $E$. ciliate aerial; $\mathrm{CBE}=$ ethanol extract of $C$. burmanni leaf; MSW = water extract of $M$. speciosa root; MAW = water extract of $M$. azedarach leaf; MAE = ethanol extract of $M$. azedarach leaf; $\mathrm{ACW}=$ water extract of $A$. catechu fruit; $\mathrm{PBE}=$ ethanol extract of $P$. betle leaf.

plant extracts (such as EIW, CBE, and ECW treatments) caused a decrease in number of soil ammonium-oxidizing bacteria close to $50 \%$ (after $14 \mathrm{~d}$ of incubation) compared with the control soil, indicating a possible toxic effect on soil microorganisms under laboratory conditions. A similar effect was observed by Lodhi and Killingbeck (1980), who reported a toxic effect on Nitrosomonas sp. of $\approx 70 \%$ over the control soil, when the compounds extracted from Pinus ponderosa douglas bark were added to soil. 2) The fine coordination in chemical properties of plant phenols. The extracted phenolic compounds can bind to $\mathrm{Ni}$ in the active center of urease or $\mathrm{Cu}$ in the active center of ammonia monooxygenase through chelate bonds. The result is that the enzymes are unable to combine with their substrates effectively, and lose their catalytic activity (Vandevivere et al., 1998). 3 ) The oxygen consumption in soil microenvironment due to the oxidation of phenolic compounds. The phenols are easily oxidized to quinines (Westermark and Eriksson, 1974). This is an oxygen-consuming process that can lead to oxygen deficiency and activity limitation for aerobes.

Two common solvents, water and ethanol, were used to extract the compounds in plant materials in the present study. The results suggested that no matter for the total solid, phenols, or the biological effects, the ethanol extracts did not display advantages compared with the water extracts. Usually, the solvents extract a large amount of phenolic compounds due to their polar nature and the high content of phenolic hydroxyl groups (Falleh et al., 2008). The extract yields and resulting inhibitory activities of plant materials are strongly dependent on the nature of extracting solvent, due to the presence of different compounds of varied chemical characteristics and polarities that may or may not be soluble in a particular solvent. Ethanol is a general solvent and tends to provide a more complete extraction of compounds with a variety of polarities, while water extracts may not contain some of the less polar compounds (Webster et al., 2008).

Urea applied to the soil is generally rapidly hydrolyzed into $\mathrm{NH}_{4}^{+}$by urease within a few days, whereas the strongest nitrification usually occurs within the first 2 weeks after incubation (Zerulla et al., 2001). When using urea as fertilizer source, combined application of urease and nitrification inhibitors is generally adopted to simultaneously slow down the hydrolysis rate of urea and the nitrification rate of its hydrolysis product $\mathrm{NH}_{4}{ }^{+}$. Pereira et al. (2013) indicated that combined application of urease and nitrification inhibitors could not only prolong the hydrolysis time of urea, but also maintain relatively high $\mathrm{NH}_{4}^{+}$content in soil during subsequent incubation. However, simultaneous application of two kinds of inhibitors will significantly increase both the fertilizer costs and the risks of environmental and agricultural pollution. Mohanty et al. (2008) found that applying neem extracts could prolong the hydrolysis process of urea twice at least and could postpone the nitrification by 7-21 d. This study showed that EIW and MAW extracts could inhibit both urea hydrolysis and nitrification. Therefore, the application of these extracts in agricultural production can not only improve the use efficiency of $\mathrm{N}$ fertilizers but also protect the agricultural ecological environment.

This research is an early step for developing efficient, inexpensive, and environmentally friendly plant-derived urease and nitrification inhibitors. EIW and MAW extracts represented fine abilities in regulating soil $\mathrm{N}$ transformation. However, it is not yet known whether application of these medicinal plant materials would have an adverse effect on the growth of plants. Further research will thus be necessary to examine their 

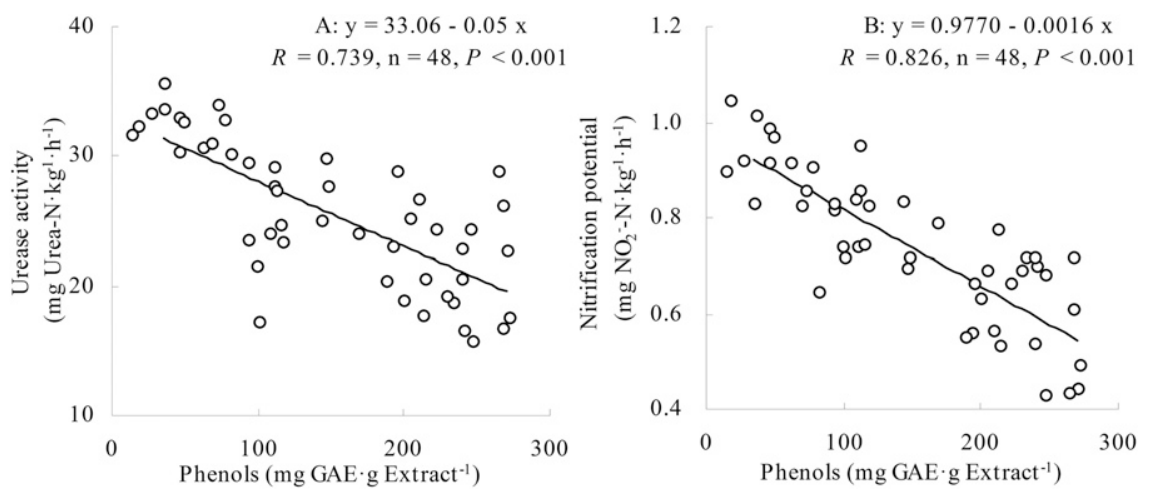

Fig. 4. Linear correlation between the phenols content in the tropical medicinal plant extracts and urease activity (UA, A) and nitrification potential (NP, B) of the soil treated with the extracts based on the short-term (5-h) incubation experiments.

influence on various crops and weed species, as well as their residual time and breakdown products in soil.

\section{Conclusions}

This study further supports the view that some tropical medicinal plants are promising sources of natural urease/nitrification inhibitors regulating soil $\mathrm{N}$ transformation. The total solid yield and phenols content differed significantly among 48 investigated plant extracts obtained with water and ethanol. A significant correlation between phenols content and soil UA/NP was found, indicating that phenolic compounds are the major contributors to the inhibitory properties of these plant extracts. Further studies indicated that the water extracts of $E$. indica aerial and $M$. azedarach leaf, containing high contents of phenols, exhibited notable urease and nitrification inhibitory effects and reduced the number of soil ammonia-oxidizing bacteria, being promising sources of natural inhibitors for soil $\mathrm{N}$ transformation. Therefore, the effects of the extracts of $E$. indica and $M$. azedarach on soil $\mathrm{N}$ transformation in soilcrop systems and their by-effects on soil microbes and plants should be the objective of further research.

\section{Literature Cited}

Abbasi, M.K. and M. Manzoor. 2013. Effect of soil-applied calcium carbide and plant derivatives on nitrification inhibition and plant growth promotion. Intl. J. Environ. Sci. Technol. 10:961-972.

Arango, J., D. Moreta, J. Núñez, K. Hartmann, M. Domínguez, M. Ishitani, and I. Rao. 2014. Developing methods to evaluate phenotypic variability in biological nitrification inhibition (BNI) capacity of Brachiaria grasses. Trop. Grassl. 2:6-8.

Arora, K. and A. Srivastava. 2013. Nitrogen losses due to nitrification: Plant based remedial prospects. Intl. J. Bioassays 2:984-991.

Baldwin, I.T., R.K. Olson, and W.A. Reiners. 1983. Protein binding phenolics and the inhibition of nitrification in subalpine balsam fir soils. Soil Biol. Biochem. 15:419-423.

Castaldi, S., A. Carfora, A. Fiorentino, A. Natale, A. Messere, F. Miglietta, and M.F. Cotrufo. 2009. Inhibition of net nitrification activity in a Mediterranean woodland: Possible role of chemicals produced by Arbutus unedo. Plant Soil 315:273-283.

DeLuca, T., M.C. Nilsson, and O. Zackrisson. 2002. Nitrogen mineralization and phenol accumulation along a fire chronosequence in northern Sweden. Oecologia 133:206-214.

Falleh, H., R. Ksouri, K. Chaieb, N. KarrayBouraoui, N. Trabelsi, M. Boulaaba, and C. Abdelly. 2008. Phenolic composition of Cynara cardunculus $\mathrm{L}$. organs, and their biological activities. C. R. Biol. 331:372-379.

Fonseca, J.M., J.W. Rushing, N.C. Rajapakse, R.L. Thomas, and M.B. Riley. 2006. Potential implications of medicinal plant production in controlled environments: The case of feverfew (Tanacetum parthenium). HortScience 41:531-535.

Kiran, U. and D.D. Patra. 2003. Medicinal and aromatic plant materials as nitrification inhibitors for augmenting yield and nitrogen uptake of Japanese mint (Mentha arvensis L. Var. Piperascens). Bioresour. Technol. 86:267-276.

LeRoux, X., L. Abbadie, R. Lensi, and D. Serça. 1995. Emission of nitrogen monoxide from African tropical ecosystems: Control of emission by soil characteristics in humid and dry savannas of West Africa. J. Geophys. Res. 100:23133-23142.

Lodhi, M.A.K. and K.T. Killingbeck. 1980. Allelopathic inhibition of nitrification and nitrifying bacteria in a ponderosa pine (Pinus ponderosa Dougl.) community. Amer. J. Bot. 76:1423-1429.

Mohanty, S., A.K. Patra, and P.K. Chhonkar. 2008 Neem (Azadirachta indica) seed kernel powder retards urease and nitrification activities in different soils at contrasting moisture and temperature regimes. Bioresour. Technol. 99:894-899.

Northup, R.R., Z. Yu, R.A. Dahlgren, and K.A. Vogt. 1995. Polyphenol control of nitrogen release from pine litter. Nature 377:227-229.

Opoku, A., B. Chaves, and S. De Neve. 2014. Neem seed oil: A potent nitrification inhibitor to control nitrate leaching after incorporation of crop residues. Biol. Agric. Hort. 30:145-152.

Patra, D.D., U. Kiran, and P. Pande. 2006. Urease and nitrification retardation properties in natural essential oils and their by-products. Commun. Soil Sci. Plan. 37:1663-1673.

Pereira, J., A.S. Barneze, T.H. Misselbrook, J. Coutinho, N. Moreira, and H. Trindade. 2013. Effects of a urease inhibitor and aluminium chloride alone or combined with a nitrification inhibitor on gaseous $\mathrm{N}$ emissions following soil application of cattle urine. Biosystems Eng. 115:396-407.

Purnomo, D., Suryono, T. D. Sulistyo, S. Budiastuti, and Supriyadi. 2012. Potential of varies trees litter containing tannin on agroforestry system as nitrification inhibitor for increasing nitrogen fertilizer efficiency for soybean. J Agr. Sci. Tech. B 2:198-203.

Rauha, J.P., S. Remes, M. Heinonen, A. Hopia, M. Kähkönen, T. Kujala, K. Pihlaja, H. Vuorela, and P. Vuorela. 2000. Antimicrobial effects of finnish plant extracts containing flavonoids and other phenolic compounds. Intl. J. Food Microbiol. 56:3-12.

Schinner, F., R. Öhlinger, and E. Kandeler. 1996. Methods in soil biology. Springer-Verlag Berlin Heidelberg Press, Berlin, Germany.

Schmidt, B.M. 2012. Responsible use of medicinal plants for cosmetics. HortScience 47:985-991.

Singleton, V.L., R. Orthofer, and R.M. LamuelaRaventos. 1999. Analysis of total phenols and other oxidation substrates and antioxidants by means of Folin-ciocalteu reagent. Methods Enzymol. 299:152-178.

Subbarao, G.V., K.L. Sahrawat, K. Nakahara, I.M. Rao, M. Ishitani, C.T. Hash, and J.C. Lata. 2013. A paradigm shift towards low-nitrifying production systems: The role of biological nitrification inhibition (BNI). Ann. Bot. (Lond.) 112:297-316.

Subbarao, G.V., K.L. Sahrawat, K. Nakahara, T. Ishikawa, M. Kishii, I.M. Rao, and J.C. Lata. 2012. Biological nitrification inhibition: A novel strategy to regulate nitrification in agricultural systems. Adv. Agron. 114:249-302.

Subbarao, G.V., M. Kishii, K. Nakahara, T. Ishikawa, T. Ban, H. Tsujimoto, T.S. George, W.L. Berry, C.T. Hash, and O. Ito. 2009. Biological nitrification inhibition (BNI): Is there potential for genetic interventions in the Triticeae? Breed. Sci. 59:529-545.

Suescun, F., L. Paulino, E. Zagal, C. Ovalle, and C. Muñoz. 2012. Plant extracts from the Mediterranean zone of Chile potentially affect soil microbial activity related to $\mathrm{N}$ transformations: A laboratory experiment. Acta Agr. Scand. BS. P. 62:556-564.

Tabatabai, M.A. 1994. Soil enzymes, p. 775-833. In: Weaver, R.W., and J.S. Angle (eds.) Method of soil analysis, Part 2-Microbiological and biochemical properties. Marcel Dekker Press, New York.

Upadhyay, R.K., D.D. Patra, and S.K. Tewari. 2011. Natural nitrification inhibitors for higher nitrogen use efficiency, crop yield, and for curtailing global warming. J. Trop. Agr. 49: 19-24.

Vandevivere, P., E. Ficara, C. Terras, E. Julies, and W. Verstraete. 1998. Copper-mediated selective removal of nitrification inhibitors from industrial wastewaters. Environ. Sci. Technol. 32:1000-1006.

Webster, D., P. Taschereau, R.J. Belland, C. Sand, and R.P. Rennie. 2008. Antifungal activity of medicinal plant extracts: Preliminary screening studies. J. Ethnopharmacol. 115:140-146.

Westermark, U. and K.E. Eriksson. 1974. Carbohydrate-dependent enzymic quinone reduction during lignin degradation. Acta Chem. Scand. B 28:204-208.

Zaman, M., S. Saggar, J.D. Blennerhassett, and J. Singh. 2009. Effect of urease and nitrification inhibitors on $\mathrm{N}$ transformation, gaseous emissions of ammonia and nitrous oxide, pasture yield and $\mathrm{N}$ uptake in grazed pasture system. Soil Biol. Biochem. 41:1270-1280.

Zerulla, W., T. Barth, J. Dressel, K. Erhardt, K.H. von Locquenghien, G. Pasda, M. Rädle, and A. Wissemeier. 2001. 3, 4-Dimethylpyrazole phosphate (DMPP) - A new nitrification inhibitor for agriculture and horticulture. Biol. Fertil. Soils 34:79-84. 